\title{
OPEN Ribosomal protein UL3 targets E2F1 and Cyclin D1 in cancer cell response to nucleolar stress
}

\author{
Annalisa Pecoraro ${ }^{1}$, Pietro Carotenuto $\mathbb{1}^{2}{ }^{2}$, Giulia Russo ${ }^{1 *}$ \& Annapina Russo ${ }^{1 *}$ \\ Several experimental strategies in the treatment of cancer include drug alteration of cell cycle \\ regulatory pathways as a useful strategy. Extra-ribosomal functions of human ribosomal protein L3 \\ (uL3) may affect DNA repair, cell cycle arrest and apoptosis. In the present study, we demonstrated \\ that $\mathrm{UL} 3$ is required for the activation of $\mathrm{G1} / \mathrm{S}$ transition genes. Luciferase assays established that \\ uL3 negatively regulates the activity of E2F1 promoter. Induced ribosome-free UL3 reduces Cyclin D1 \\ mRNA and protein levels. Using protein/protein immunoprecipitation methods, we demonstrated \\ that uL3 physically interacts with PARP-1 affecting E2F1 transcriptional activity. Our findings led to the \\ identification of a new pathway mediated by UL3 involving E2F1 and Cyclin D1 in the regulation of cell \\ cycle progression.
}

The cell cycle is a regulatory process by which cells grow, replicate their DNA and divide. It is controlled by a complex series of multiple, different signaling pathways. In cancer, as a consequence of genetic mutations, the strictly controlled process fails to correctly function resulting in uncontrolled cell proliferation ${ }^{1}$.

Perturbations of rRNA synthesis and/or processing are closely related to cell cycle alteration and cancer progression ${ }^{2}$. Ribosome biogenesis takes place in the nucleolus. Although the nucleolus represents mainly the site for ribosomal biogenesis and assembly, it is now clear that it is associated with many different cellular functions ${ }^{3}$. Recent data show that nucleolus acts as a sensor of cellular stress and responds by reorganizing its morphological architecture and protein content ${ }^{4}$. Nucleolar stress has been demonstrated to activate $\mathrm{p} 53$-dependent and p53-independent stress response signaling pathways with consequent cell cycle arrest and/or apoptosis ${ }^{5}$.

A group of ribosomal proteins (RP) affect cell cycle progression through the activation of different mechanisms. To cite, in Jurkat T-lymphoma cells the induced production of uL30 leads to cell cycle arrest in G1 phase; the overexpression of eL15 enhances cell proliferation; and the down-regulation of eL15 suppresses tumorigenicity of cancer cells in nude mice. RPs extraribosomal functions are also needed for normal cell proliferation. For example, uS3 is a microtubule-associated protein (MAP) and its depletion is associated to metaphase arrest and alteration in chromosome movement during cell division ${ }^{6}$.

We have recently demonstrated that the over-expression of uL3 causes cell cycle arrest in G1 phase by modulating p21 levels ${ }^{7-10}$. However, the mechanism through which, in presence of uL3, coordination between nucleolar stress and cell cycle progression occurs has yet to be elucidated.

Cell cycle progression through G1 phase is an activity strictly controlled in cells, it can be separated in early-G1 trascriptional activation of early genes, mid-G1 activation of cyclin D/cdk4/6, and late-G1 activation of cyclin $\mathrm{E} / \mathrm{cdk} 2^{11}$. In particular, the phosphorylation of retinoblastoma protein (pRb) family mediated by cdk/ cyclin complexes is necessary for the transition from the $\mathrm{G} 1$ to the $\mathrm{S}$ phase of cell cycle. Phosphorylation of $\mathrm{pRb}$ leads to the release of E2F1 which in turn up-regulates the transcription of genes required to entry into late G1/S phase and further ${ }^{12}$. E2F1 function is subject to complex control mechanisms during cell cycle progression. In fact, prolonged activation of E2F1 expression is associated to G1 checkpoint activation and apoptosis, that prevent inappropriate reinitiation of DNA synthesis ${ }^{13}$. The comprehension of the molecular mechanisms controlling G1/S transition is crucial to identify new strategies to maintain a correct regulation of cell cycle.

In this study, we demonstrate that upon drug-induced nucleolar stress, uL3 accumulates in the nucleolus and localizes in the nucleoplasm. Consequently, uL3 affects E2F1 expression levels and the activity of E2F1 promoter; acts as negative regulator of cyclin D1 expression at mRNA and protein level; interacts with PARP-1 and influences PARP-1 mediated trans-activation of E2F1 promoter. Taken together, our data show that uL3 critically

\footnotetext{
${ }^{1}$ Department of Pharmacy, University of Naples "Federico II", Via Domenico Montesano 49, 80131, Naples, Italy. ${ }^{2}$ The Institute of Cancer Research, Cancer Therapeutics Unit 15 Cotswold Road, Sutton, London, SM2 5NG, UK.

*email: giulia.russo@unina.it; annapina.russo@unina.it
} 
contributes to regulate cell cycle progression through the control of the expression and the activity of relevant genes involved in the G1/S transition of cell cycle.

\section{Results}

uL3 status influences cell migration and EMT program. We have previously demonstrated that uL3 status is associated to chemoresistance. In fact, we demonstrated that uL3 $\Delta$ HCT $116^{\mathrm{p}^{53-}-}$ - cell line in which uL3 levels were strongly lower than in parental cell line ${ }^{10}$ resulted resistant to different anticancer drugs ${ }^{14,15}$. To further characterize the effects of uL3 silencing, we investigated the effect of low levels of uL3 on cell proliferation, cell motility and epithelial-mesenchymal transition (EMT), a migratory cellular program associated with tumor development and metastasis.

Our results showed that $\mathrm{uL} 3 \Delta \mathrm{HCT} 116^{\mathrm{p} 53-1-}$ cells exhibited rates of proliferation comparable to parental cells (Supplementary Fig. S1). The wound healing ability of these cells was markedly increased in time dependent manner when compared to the wound healing ability observed in HCT $116^{\mathrm{p}^{53-1-}}$ cells (Fig. 1a, Supplementary Fig. S2). Quantitative analysis showed that after $30 \mathrm{~h}$, HCT $116^{\mathrm{p} 53-1-}$ cells filled about $50 \%$ of the wound area while $\mathrm{uL} 3 \Delta$ HCT $116^{\mathrm{p}^{53-1-}}$ cells filled about $80 \%$ of the wound area, demonstrating that $\mathrm{uL} 3 \Delta \mathrm{HCT} 116^{\mathrm{p} 53-/-}$ cells closed the wound faster than HCT $116^{\mathrm{p} 53-/-}$ cells. We also observed that the higher ability of uL $3 \Delta$ HCT $116^{\mathrm{p} 53-/-}$ cells to migration was associated to morphological changes. More specifically, the low expression of uL 3 in these cells was correlated to a characteristic EMT (Fig. 1b, Supplementary Fig. S3). In fact, analysis of the expression of EMT-related markers in uL3 $\Delta$ HCT $116^{\mathrm{p}^{53-1-}}$ cells, measured by western blotting, showed a significant decrease of the epithelial marker E-cadherin and an increase of the mesenchymal marker vimentin (Fig. 1c).

All these results indicated that $\mathrm{uL} 3 \Delta \mathrm{HCT} 116^{\mathrm{p} 53-/-}$ cells, in which $\mathrm{uL} 3$ levels were reduced of about $70 \%$ compared to those in parental cell line, displayed rates of proliferation similar to the parental cell line, an increase in cell motility and a characteristic EMT phenotype.

uL3 localizes in the nucleoplasm upon Act D exposure. The observed important role of uL3 in cell motility and de-differentiation, prompted us to explore extra-ribosomal functions of uL3 possibly leading to enhance cell responsiveness to anticancer treatments. Published data report that the alteration in wound healing ability and EMT transition correlates with changes in cell cycle regulators as cyclins, cdks and CKI (refs. ${ }^{16-18}$ ). We have previously demonstrated that upon drug-induced nucleolar stress, uL3 as ribosome-free form can function mainly as transcriptional factor leading to cell cycle arrest and/or apoptosis ${ }^{5}$.

To approach the issue, primarily we monitored the intracellular localization of ribosome-free $\mathrm{uL} 3$ in condition of nucleolar stress. To this aim, HCT $116^{\mathrm{p} 53-/-}$ cells were transiently transfected with a plasmid expressing uL3 fused to GFP and treated for $18 \mathrm{~h}$ with low dose $(5 \mathrm{nM})$ of Act D. Act D is a transcription inhibitor that blocks the RNA polymerase during the elongation step. High doses of Act D inhibit the transcription of all RNA species. At lower concentrations, i.e. $5 \mathrm{nM}$, Act D specifically inhibits RNA polymerase I driven transcription activating nucleolar stress ${ }^{9,19}$

As shown in Fig. 2a and in Supplementary Fig. S4, in untreated cells uL3 protein distributed mainly in the nucleolus according to its role of ribosomal component. These data were also confirmed by experiments of biochemical fractionation demostrating that uL3 localizes in the nucleolus same as nucleolin, a well known marker of the nucleolus (Supplementary Fig. S5).

Upon Act D induced nucleolar stress, ribosome-free uL3 re-distributes and localizes largely also in the nucleoplasm (Fig. 2a,b). These results together with our previous findings demonstrating that in condition of nucleolar stress uL3 dissociates from the ribosome ${ }^{9}$, have led us to propose that in condition of Act D-induced nucleolar stress ribosome-free uL3, dissociates from the nucleolus and relocalizes in the nucleoplasm as shown in Fig. 2a.

Nevertheless, results of RT-qPCR analysis shown in Fig. 2c demonstrated that also the level of uL3 mRNA increased in this condition. Consequently, we cannot exclude that the localization of UL3 in the nucleoplasm may be due to an increase in the level of UL3 mRNA with consequent synthesis of uL3 protein that localizes, in condition of nucleolar stress, primarily in the nucleoplasm.

Reduced levels of pre-rRNA $47 \mathrm{~S}$ confirmed the induction of nucleolar stress caused by Act D treatment (Fig. 2c).

Role of uL3 on the expression of cell cycle and cell proliferation related genes. Nucleoplasm localization of uL3 upon nucleolar stress, alteration in cell motility and EMT transition prompted us to plan experiments to define its role in regulating cell cycle progression. Primarily, we analyzed the expression levels of cell cycle-related genes in condition of nucleolar stress, in presence or in absence of uL3.

HCT $116^{\mathrm{p} 53-l-}$ and $\mathrm{uL} 3 \Delta \mathrm{HCT} 116^{\mathrm{p} 53-1-}$ cells were treated with Act D $5 \mathrm{nM}$ for $18 \mathrm{~h}$. Then, total RNA extracted from cell lysates was analyzed by RT-qPCR with specific primers for the expression of proteins regulating cell cycle progression as Cyclin D1, Cyclin E1, Cyclin A and Cyclin B (Table 1). As shown in Fig. 3a, analysis of RNA levels of cell cycle checkpoint proteins in HCT $116^{\mathrm{p} 53-1-}$ demonstrated that upon nucleolar stress a strong decrease of Cyclin D1 was observed associated to a lower decrease also in Cyclin E1. The expression of Cyclin A and Cyclin B was not significantly altered suggesting that these regulatory proteins were not affected by drug treatment. Previous data demonstrated that the reduction of Cyclin D1 expression was associated to an increased sensitivity of cells to drug-induced apoptosis ${ }^{20}$, consequently we analyzed the expression of anti-apoptotic protein Bax and pro-apoptotic Bcl-2. As expected, the increase of ribosome free $\mathrm{uL} 3$ caused by drug treatment was associated to a strong induction of Bax and a decrease of Bcl-2 in HCT $116^{\mathrm{p} 53-1-}$ cells (Fig. 3c). In addition to cyclins, transition from $\mathrm{G} 1$ to the $\mathrm{S}$ phase of the cell cycle requires the inactivation of the retinoblastoma protein $(\mathrm{Rb})$ family, cell cycle inhibitors at the key G1/S restriction point, and the consequent activation of E2F $1^{11,21}$. This transcription factor regulates the expression of various proteins including Cyclin D1 and MCM2-7 that form the preinitiation complex for DNA replication ${ }^{11,13}$. In particular, it has been demonstrated that free E2F1 
a
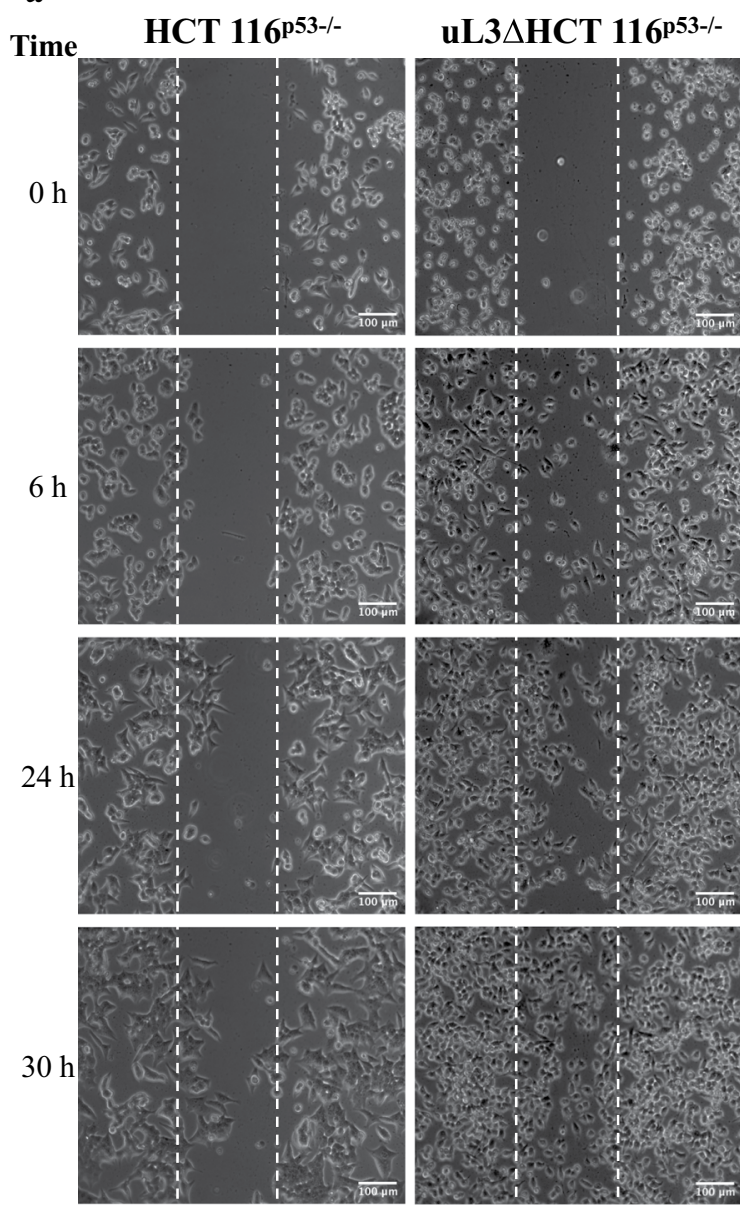

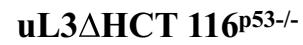
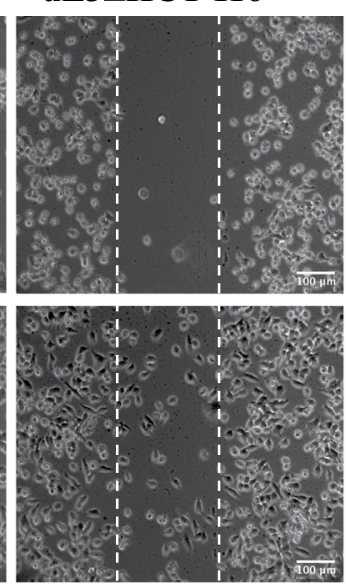

b
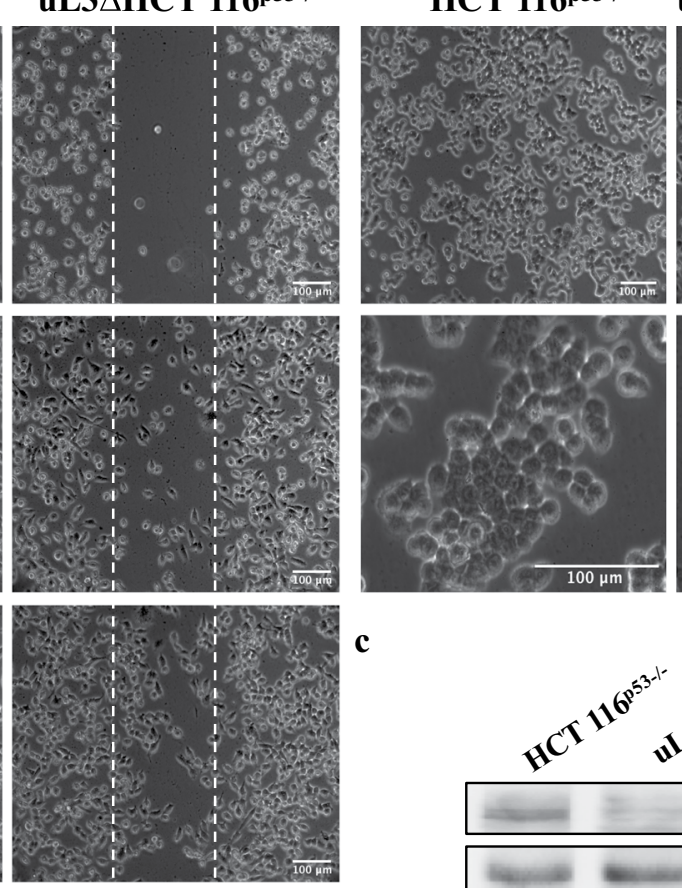

uL3 $\triangle$ HCT 116
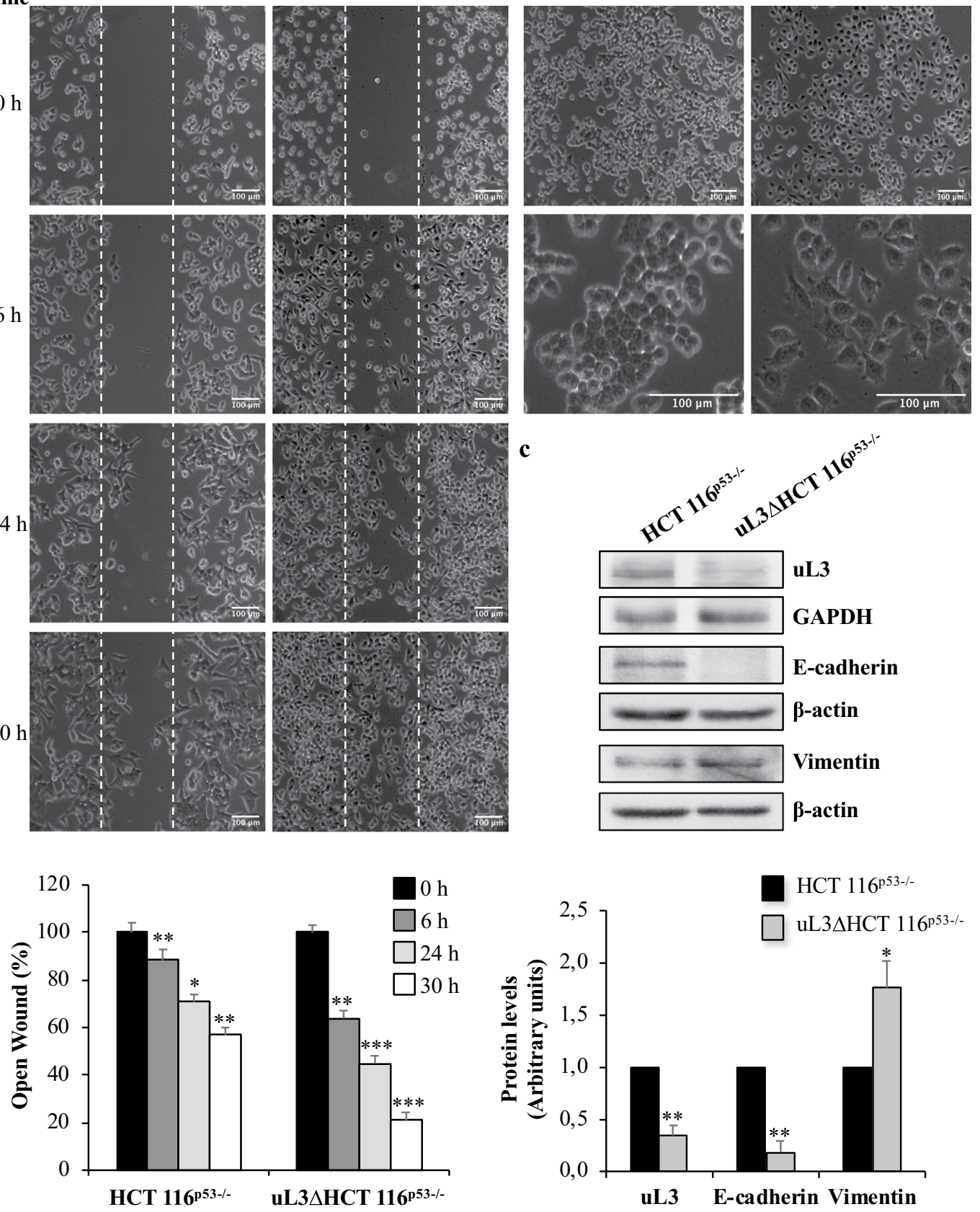

Figure 1. Effects of uL3 on cell migration and EMT program. (a) Wound widths in HCT $116^{\mathrm{p} 53-1-}$ and $\mathrm{uL} 3 \Delta \mathrm{HCT} 116^{\mathrm{p} 53-1-}$ were measured at $0,6,24$ and $30 \mathrm{~h}$ on 3 fields per well and averaged. Data are expressed as the fold-decrease of area respect to control (time 0 ) set as $100 \%$. (b) Representative bright-field microscope images of HCT $116^{\mathrm{p} 53-/-}$ and uL3 $\Delta$ HCT $116^{\mathrm{p} 53-/-}$ cell lines. Scale bar: $100 \mu \mathrm{m}$. (c) Representative western blot analysis of $\mathrm{uL} 3$ and EMT markers. Protein extracts from HCT $116^{\mathrm{p} 53-1-}$ and $\mathrm{uL} 3 \Delta$ HCT $116^{\mathrm{p} 53-1-}$ cells were analyzed by western blotting with the indicated antibodies. GAPDH and $\beta$-actin were used as loading controls. Full-length blots are presented in Supplementary Fig. S7. Quantification of signals is shown. Bars represent the mean of triplicate experiments; error bars represent the standard deviation. $* \mathrm{p}<0.05 ; * * \mathrm{p}<0.01$ vs. HCT $116^{\mathrm{p} 53-1-}$ cells set at 1 .

may contribute to either the activation or to the inhibition of the expression of Cyclin D1 depending on the cells context $^{22}$ and as a consequence free E2F1 can induce either apoptosis than proliferation ${ }^{22}$. Our results demonstrated that in HCT $116^{\mathrm{p} 53-1-}$ cells, Act D induced nucleolar stress did not affect Rb amount but caused a significant reduction of E2F1 levels which was associated to a decrease of Mcm6 and Mcm7 levels, thus indicating a 
a

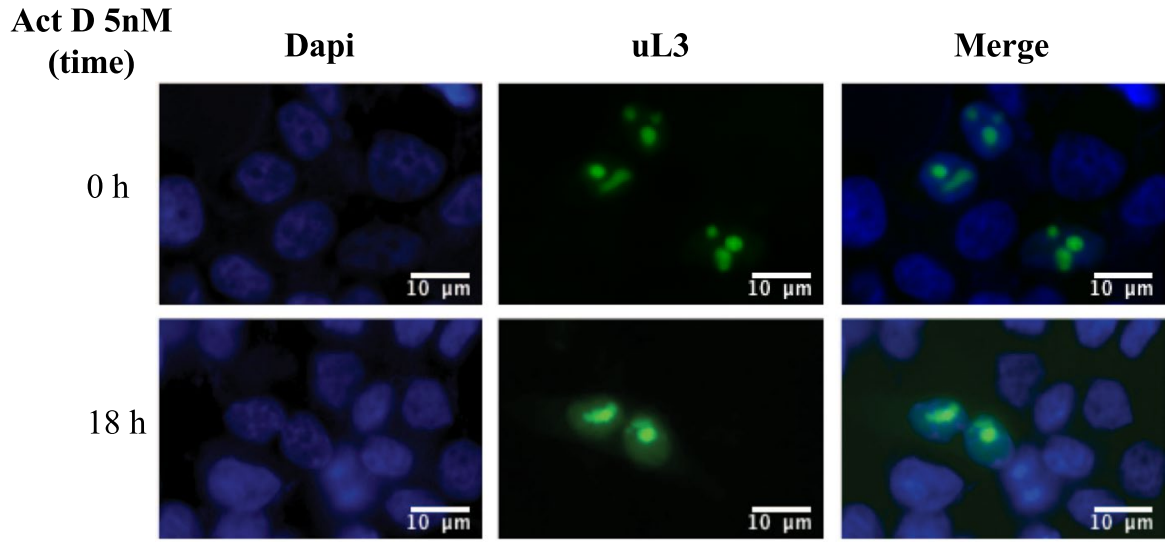

b

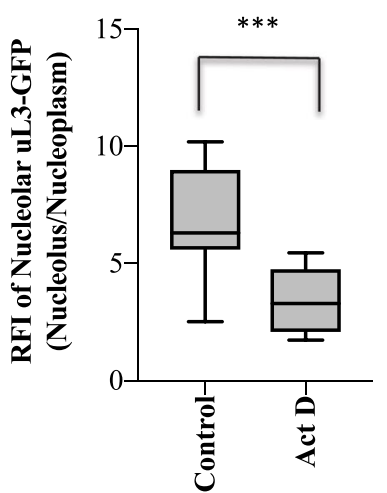

c

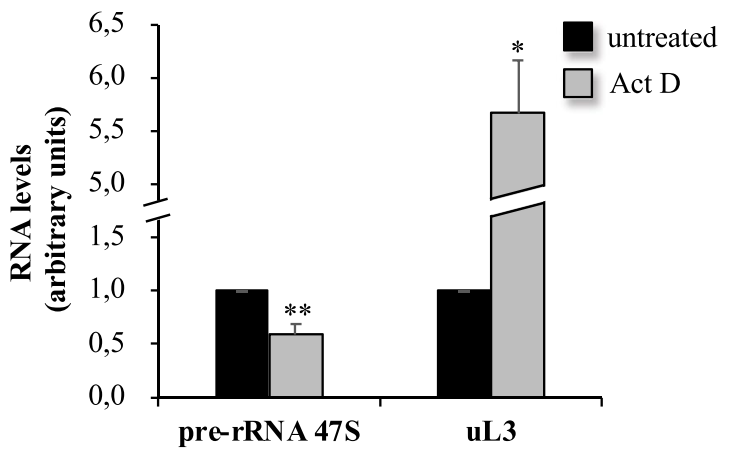

Figure 2. uL3 localizes in the nucleoplasm upon Act D exposure. (a) Representative fluorescent microscopy images of HCT $116^{\mathrm{p} 53-1-}$ cells transiently transfected with pGFP-uL3 and treated with Act D $5 \mathrm{nM}$ for $18 \mathrm{~h}$. DAPI is used as a nuclear stain and shown in blue; GFP-uL3 dependent fluorescence is shown in green. Scale bar: $10 \mu \mathrm{m}$. (b) Quantification of signal was shown. Nucleolar/nucleoplasmic RFI ratio of uL3-GFP $(\mathrm{n}=31)$ were displayed. Mean \pm s.e.m. Unpaired t-test. $* * * \mathrm{P}<0.001$. (c) RT-qPCR of total RNA extracted from HCT $116^{\mathrm{p} 53-1-}$ cells treated with Act D $5 \mathrm{nM}$ for $18 \mathrm{~h}$ with primers specific for uL3 and $47 \mathrm{~S}$ pre-rRNA (Table 1 ). Bars represent the mean of triplicate experiments; error bars represent the standard deviation. $* \mathrm{p}<0.05 ; * * \mathrm{p}<0.01$ vs. untreated cells set at 1 .

reduction of DNA synthesis (Fig. 3c). In order to understand whether the observed effects were dependent on uL3 status, we analyzed the expression profiles of tested genes when uL3 gene expression was silenced. To this aim, $\mathrm{uL} 3 \Delta$ HCT $116^{\mathrm{p} 53-1-}$ cells were treated with Act D for $18 \mathrm{~h}$ and total RNA extracted was analyzed with the same primers (Table 1). Of interest, when uL3 was silenced, the treatment with Act D resulted in an increase of Cyclin D1 and E2F1 expression levels (Fig. 3b,d). As in parental cell line, the expression of other members of cyclin family was not altered (Fig. 3b). Furthermore, Act D was uneffective on MCM6 and MCM7 expression (Fig. 3d). Of interest, the treatment with Act D in absence of $\mathrm{uL} 3$ failed to induce apoptosis as demonstrated by Bcl-2 and Bax protein levels.

These data suggest Cyclin D1 and E2F1 are important players in uL3 cell response to nucleolar stress induced by Act $\mathrm{D}$ in colon cancer cells harboring p53 deletion.

UL3 negatively regulates Cyclin D1 mRNA and protein stability. Since our data demonstrated that uL3 status influences Cyclin D1 levels in colon cancer cells, we proceeded in the attempt to characterize the specific molecular targets of uL3 along the expression process of Cyclin D1.

A number of studies have shown that cellular accumulation of Cyclin D1 is under tight control and its expression is regulated at multiple levels, including mRNA and protein stability ${ }^{23}$. Consequently, we investigated whether uL3 could affect Cyclin D1 expression at mRNA and protein levels. To this aim, cells were incubated with Act D $(2 \mu \mathrm{g} / \mathrm{mL})$ to inhibit nascent mRNA synthesis. Total RNA was obtained from HCT $116^{\mathrm{p}^{53-1-}}$ and $\mathrm{uL} 3 \Delta \mathrm{HCT} 116^{\mathrm{p} 53-1-}$ cells at the indicated times $(2,4$ and $8 \mathrm{~h})$ and Cyclin D1 mRNA levels were analyzed by qRT-PCR. The results showed that in HCT $116^{\mathrm{p} 53-1-}$ the amount of Cyclin D1 mRNA was lower than in $\mathrm{uL} 3 \Delta$ HCT $116^{\mathrm{p} 53-1-}$ at all time points. In particular, the levels of Cyclin D1 mRNA in HCT $116^{\mathrm{p}^{53-1-}}$ were approximately $50 \%$ lower compared to Cyclin D1 mRNA in uL3 $\Delta$ HCT $116^{\mathrm{p}^{53-1-}}$ after $8 \mathrm{~h}$ of Act D treatment 


\begin{tabular}{|l|l|}
\hline Gene & Sequence \\
\hline CycA & $\begin{array}{l}\text { Forward: 5'-TTCATTTAGCACTCTACACAGTCACGG-3' } \\
\text { Reverse: 5'-TTGAGGTAGGTCTGGTGAAGGTCC-3' }\end{array}$ \\
\hline CycB & $\begin{array}{l}\text { Forward: 5'-CAGTCAGACCAAAATACCTACTGGGT-3' } \\
\text { Reverse: 5'-ACACCAACCAGCTGCAGCATCTTCTT-3' }\end{array}$ \\
\hline CycD1 & $\begin{array}{l}\text { Forward: 5'-ACGGCCGAGAAGCTGTGCATC-3' } \\
\text { Reverse: 5'-CCTCCGCCTCTGGCATTTTGGAG-3' }\end{array}$ \\
\hline CycE1 & $\begin{array}{l}\text { Forward: 5'-TGAGCCGAGCGGTAGCTGGT-3' } \\
\text { Reverse: 5'-GGGCTGGGGCTGCTGCTTAG-3' }\end{array}$ \\
\hline Bax & $\begin{array}{l}\text { Forward: 5'-CCCGAGAGGTCTTTTCCGAG-3' } \\
\text { Reverse: 5'-CCAGCCCATGATGGTTCTGAT-3' }\end{array}$ \\
\hline 3-actin & $\begin{array}{l}\text { Forward: 5'-CCAACCGCGAGAAGATGA-3' } \\
\text { Reverse: 5'-CCAGAGGCGTACAGGGATAG-3' }\end{array}$ \\
\hline Bcl-2 & $\begin{array}{l}\text { Forward: 5'-ATGTGTGTGGAGAGCGTCAACC-3' } \\
\text { Reverse: 5'-GCATCCCAGCCTCCGTTATC-3' }\end{array}$ \\
\hline E2F1 & $\begin{array}{l}\text { Forward: 5'-GTGTAGGACGGTGAGAGCAC-3' } \\
\text { Reverse: 5'-TCAAGGGTAGAGGGAGTTGG-3' }\end{array}$ \\
\hline MCM6 & $\begin{array}{l}\text { Forward: 5'-ATCCCTCTTGCCAAGGATTT-3' } \\
\text { Reverse: 5'-GAAAAGTTCCGCTCACAAGC-3' }\end{array}$ \\
\hline MCM7 & $\begin{array}{l}\text { Forward: 5'-CACGGAGTCTCTCAGCACAG-3' } \\
\text { Reverse: 5'-AACATCTGTCTGATGGGGGA-3' }\end{array}$ \\
\hline Rb & $\begin{array}{l}\text { Forward: 5'-ATTCTGCATTGGTGCTAAAAG-3' } \\
\text { Reverse: 5'-CTCCTGTTCTGACCTCGC-3' }\end{array}$ \\
\hline uL3 & $\begin{array}{l}\text { Forward: 5'-CAAAGGCTACAAAGGGGT-3' } \\
\text { Reverse: 5'-CTCAGTGCGGTGATGGTAG-3' }\end{array}$ \\
\hline pre-rRNA 47S & $\begin{array}{l}\text { Forward: 5'-GCTGACACGCTGTCCTCTG-3' } \\
\text { Reverse: 5'-ACGCGCGAGAGAACAGCAG-3' }\end{array}$ \\
\hline
\end{tabular}

Table 1. Oligonucleotide sequences used in qPCR analysis.

(Fig. 4a). These results indicate that the down-regulation of Cyclin D1 mRNA levels observed in HCT 116 $6^{\mathrm{p} 53-/-}$ following Act D treatment could be due partially to uL3-mediated decrease in Cyclin D1 mRNA stability. Next, we performed experiments to test a role of $\mathrm{uL} 3$ in the control of Cyclin D1 protein stability. To this aim HCT $116^{\mathrm{p} 53-1-}$ and $\mathrm{uL} 3 \Delta \mathrm{HCT} 116^{\mathrm{p} 53-1-}$ cells were treated with cycloheximide at different time points $(10,20,30,60$ and $90 \mathrm{~min}$ ). Then, cell lysates were immunoblotted with anti-Cyclin D1 and anti- $\beta$-actin antibodies. Analysis of the rate of disappearance of the protein following cycloheximide treatment clearly demonstrated that silencing of uL3 was associated to an increase of Cyclin D1 stability (Fig. 4b).

All these data suggest that uL3 is involved in the regulation of Cyclin D1 expression by altering the stability either at mRNA than at protein levels.

Role of UL3 on E2F1 protein levels and transcription activity of E2F1 gene. It is known that in late G1 hyperphosphorylation of Rb by cyclin-dependent kinases (cdks) results in the release of E2F1. Free E2F1 transactivates the expression of E2F1-responsive genes important for induction of S phase progression ${ }^{11,24}$. To understand the biological effect of the observed reduction of Cyclin D1 expression in presence of uL3, we firstly analyzed the protein levels of $\mathrm{E} 2 \mathrm{~F} 1$ and $\mathrm{Rb}$ in condition of ActD induced nucleolar stress in presence or absence of $\mathrm{uL} 3$. To this aim, HCT $116^{\mathrm{p} 53-1-}$ cells and uL3 $\Delta$ HCT $116^{\mathrm{p} 53-1-}$ cells were treated with Act D $5 \mathrm{nM}$ and $18 \mathrm{~h}$ later, proteins from the samples were extracted and analyzed by western blotting. As shown in Fig. 5a, in HCT $116^{\mathrm{p} 53-1-}$ cells, the treatment with Act D caused an increase of B23 and p21 levels, markers of nucleolar stress. In this condition, the intracellular amounts of pRb-Ser612 did not change while the E2F-1 and Cyclin D1 levels decreased (Fig. 5b). These results indicated that, in condition of nucleolar stress, in cells expressing uL3, the amounts of E2F1 and Cyclin D1 decreased significatively respect to the levels of unstressed cells. In untreated $\mathrm{uL} 3 \Delta$ HCT $116^{\mathrm{p} 53-1-}$ cells, p21 and B23, as expected, were down-regulated (Fig. 5a). Of interest, E2F1 and Cyclin $\mathrm{D} 1$ resulted up-regulated in these cells, while the levels of pRb-Ser612 were not notably altered (Fig. 5b). These data suggest that the lack of uL3 in uL3 $\Delta$ HCT $116^{\mathrm{p} 53-1-}$ cells activates a new uL3/E2F-1/CycD1 pathway that is independent from $\mathrm{Rb}$ status. It is important to note that drug treatment in absence of $\mathrm{uL} 3$ produced only a slight decrease of E2F1 whereas Cyclin D1 expression was up-regulated extensively in this condition (Fig. 5b).

The effect of $\mathrm{uL} 3$ on the expression profile of E2F1 prompted us to investigate the ability of uL3 to control the activity of E2F1 promoter by using a reporter luciferase assay. To this aim, HCT $116^{\mathrm{p} 53-1-}$ and $\mathrm{uL} 3 \Delta \mathrm{HCT}$ $116^{\mathrm{p} 53-1-}$ cells were transiently transfected with a plasmid carrying E2F1 full length promoter and, $24 \mathrm{~h}$ later, luciferase activity in cell lysates was analyzed. We found that the activation of E2F1 promoter was dramatically increased in absence of uL3 (Fig. 5c).

To verify that $\mathrm{uL} 3 \Delta \mathrm{HCT} 116^{\mathrm{p} 53-/-}$ cells did not acquire additional alterations in addition to uL3 depletion, we have analyzed the role of $\mathrm{uL} 3$ in the transactivation of E2F1 promoter in condition of transient $\mathrm{uL} 3$ silencing. To this aim, HCT $116^{\mathrm{p} 53-1-}$ cells were transiently transfected with siRNA specific for uL3 (Supplementary Fig. 6a). $48 \mathrm{~h}$ later, cell lysates were subjected to luciferase assay. Results shown in Fig. $5 \mathrm{c}$ demonstrate that transient depletion of uL3 caused an effect similar to that obtained with stable silencing of uL3 indicating that the alteration of E2F1 promoter activity was specifically due to the absence of $\mathrm{uL} 3$. In addition, HCT $116^{\mathrm{p} 53-1-}$ cells were transiently transfected with pHA-uL3, a plasmid expressing uL3 fused to HA (Supplementary Fig. 6b). 24h 
a

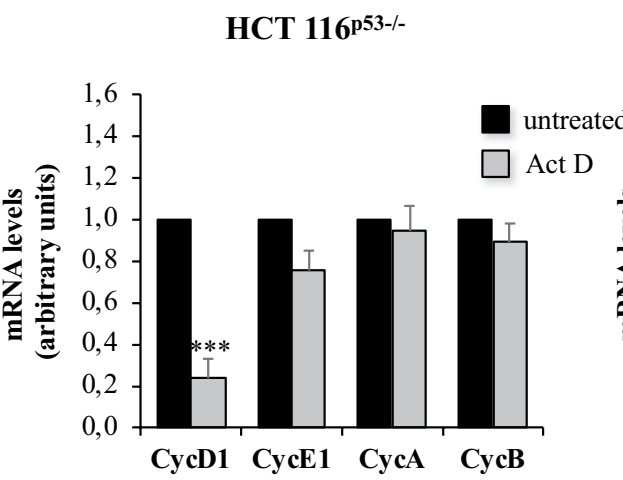

c

HCT 116 b

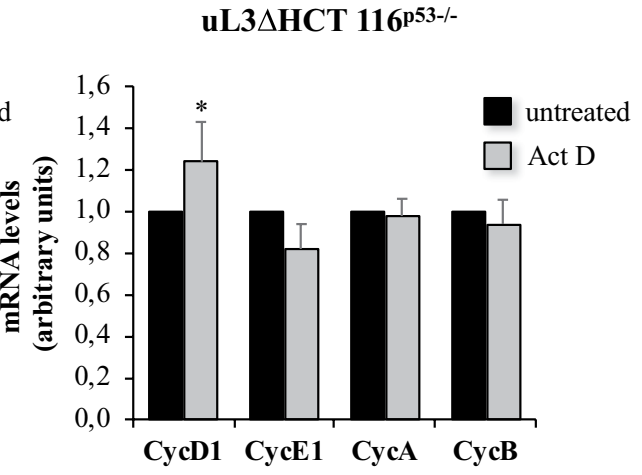

d
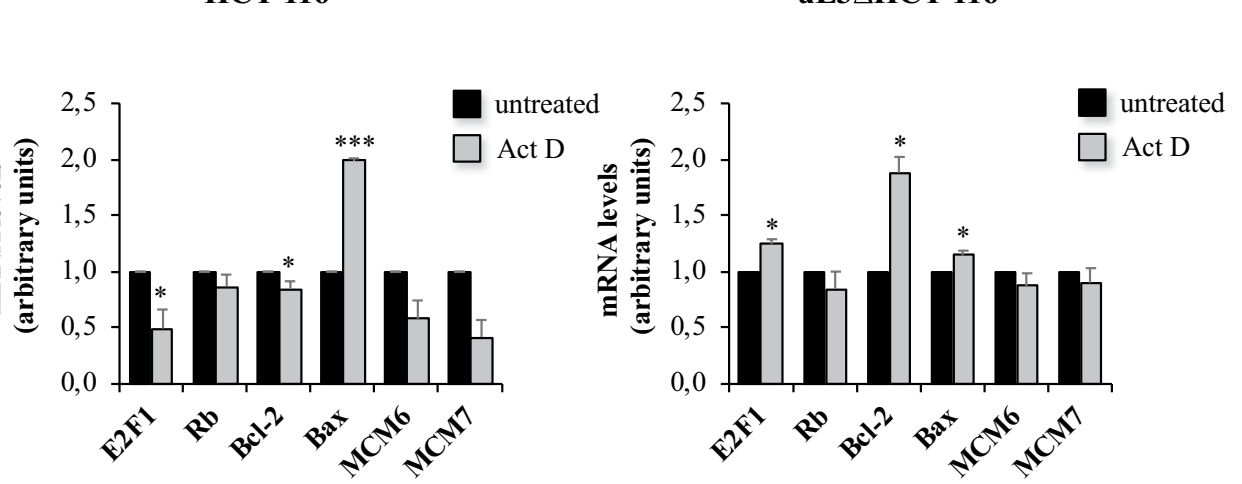

Figure 3. Act $D$ treatment is associated to the uL3-mediated regulation of cell cycle and cell proliferation related genes. Total RNA from HCT $116^{\mathrm{p} 53-{ }^{-1}}$ cells $(\mathbf{a}, \mathbf{c})$ and $\mathrm{uL} 3 \Delta \mathrm{HCT} 116^{\mathrm{p} 53-{ }^{5-}}$ cells $(\mathbf{b}, \mathbf{d})$, untreated or treated with Act D $5 \mathrm{nM}$ for $18 \mathrm{~h}$, was subjected to RT-qPCR with primers specific for the indicated genes (Table 1). Quantification of signals is shown. Bars represent the mean of triplicate experiments; error bars represent the standard deviation. ${ }^{*} \mathrm{p}<0.05 ; * * * \mathrm{p}<0.001$ vs. untreated cells set at 1 .

later, luciferase activity was measured. As shown in Fig. 5c, the effect observed upon uL3 silencing was rescue by uL3 transfection.

These results clearly indicated that $\mathrm{uL} 3$ plays a critical role in the regulation of E2F1 transcriptional activity. In particular, results of luciferase reporter analysis suggest that uL3 acts as a specific repressor of E2F1 promoter activity.

To further verify this hypothesis, we performed luciferase assay in HCT $116^{\mathrm{p} 53-/-}$ cells in condition of uL3 overexpression. Cells were transiently transfected with increasing amount of pHA-uL3. 24h later, luciferase activity in cell lysates was measured. As shown in Fig. 5d, the enforced expression of uL3 was associated to the down-regulation of E2F1 gene promoter trans-activation in a dose-dependent manner.

PARP-1 is a novel uL3-interacting protein. To better understand the role of uL3 on the transactivation of E2F1 promoter we wondered whether uL3 physically interacted with Poly(ADP-ribose) polymerase 1 (PARP-1), the main $\mathrm{E} 2 \mathrm{~F} 1$ positive regulator in cells ${ }^{25}$. To address this issue, we conducted co-immunoprecipitation experiments. Figure 6 a shows the results of the experiments in which uL3 and PARP-1 were specifically immunoprecipitated from cell extracts by using antibodies against the endogenous proteins. Immunoprecipitated proteins were separated by SDS-PAGE and the presence of UL3 and PARP-1 was investigated by western blotting in the reciprocally immunoprecipitated complexes. The results of these experiments showed that uL 3 and PARP-1 were co-immunoprecipitated, thus indicating that they can associate in vivo. Note the absence of signal in IgG immunocomplex.

Next, we investigated the functional relevance of the protein complex uL3-PARP-1 in the control of E2F1 promoter activation. To this aim, reporter luciferase assays were performed. Specifically, the E2F1 reporter plasmid was transiently transfected in HCT $116^{\mathrm{p} 53-l-}$ cells together with increasing amounts of expression plasmids coding for uL3 and/or PARP-1.24h after transfection, cells were analyzed for luciferase activity. As expected, the promoter activity was up-regulated upon PARP-1 over-expression. In contrast, the enforced expression of uL3 negatively regulates E2F1 promoter. Of note, in condition of uL3 over-expression, PARP-1 fails to overcome the 


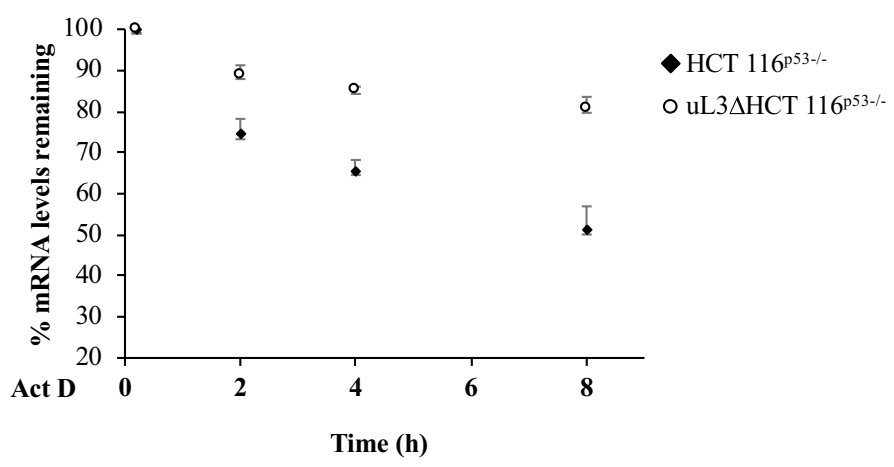

b

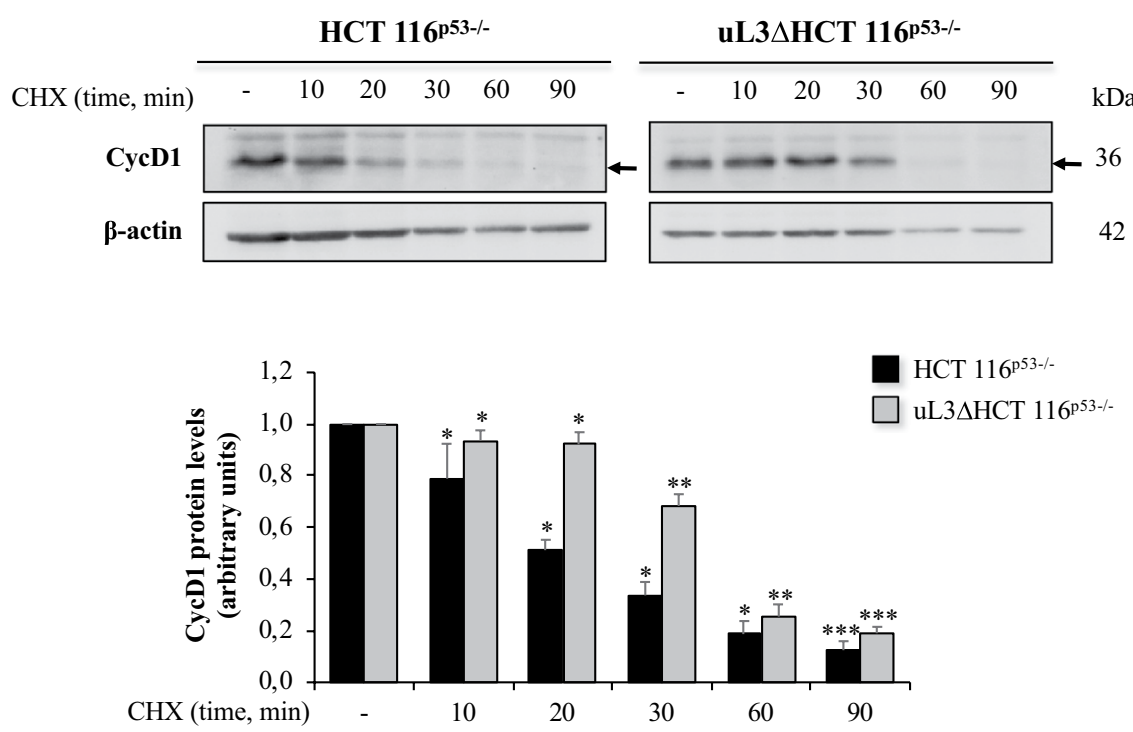

Figure 4. Effects of uL3 on Cyclin D1 mRNA and protein stability. (a) HCT $116^{\mathrm{p} 53-1-}$ and uL3 $\mathrm{HCT} 116^{\mathrm{p} 53-/-}$ cells were treated with Act $\mathrm{D}(2 \mu \mathrm{g} / \mathrm{mL})$ for $8 \mathrm{~h}$. At the indicated time points $(0,2,4$ and $8 \mathrm{~h})$, total RNA was isolated and the mRNA levels of Cyclin D1 and $\beta$-actin were determined by RT-qPCR. The relative amount of Cyclin D1 mRNA in untreated cells was set to $100 \%$ and the percentage of Cyclin D1 mRNA in cells treated with Act D was calculated accordingly. (b) HCT $116^{\mathrm{p} 53-/-}$ and $\mathrm{uL} 3 \Delta \mathrm{HCT} 116^{\mathrm{p} 53-/-}$ cells were treated with CHX $(100 \mu \mathrm{g} / \mathrm{mL})$ for $10,20,30,60$ and $90 \mathrm{~min}$. Then, cell lysates were immunoblotted with anti-Cyclin D1 and anti$\beta$-actin antibodies. Full-length blots are presented in Supplementary Fig. S8. Quantification of signals is shown. Bars represent the mean of triplicate experiments; error bars represent the standard deviation. $* * * \mathrm{P}<0.001, * * \mathrm{P}<0.01, * \mathrm{P}<0.05$ vs. untreated cells set at 1 .

uL3 mediated down -regulation of E2F1 promoter (Fig. 6b). These data suggest that uL3 controls PARP-1 mediated activation of E2F1 promoter.

\section{Discussion}

Some ribosomal proteins have extra-ribosomal functions not strictly related to protein synthesis and it is now clear that a connection between alterations in ribosomal biology and cancer exists ${ }^{26}$. In particular, an association between alteration in the expression of ribosomal proteins and cancer development and/or chemioresistance is often observed. Loss of $60 \mathrm{~S}$ uL18 and uL16 proteins has been seen in multiple myeloma and acute myeloid leukemia ${ }^{27}$; eL19, eL8 and eL37 have been found over-expressed in prostate cancer ${ }^{28,29}$; eL15 and eL19 in gastric cancer ${ }^{6}$. All these findings raise the question on how alterated levels of ribosomal proteins increase malignancy. uL3 is a crucial component of the ribosomal peptidyltransferase center and has a role in aminoacyl-tRNA binding, peptidyltransferase activity, translational frame maintenance and elongation ${ }^{30}$. uL3 is a member of a subset of RPs that as free proteins are implicated in various important events of the cell life. As free form regulates its own expression through the generation of mRNA isoforms that are target of nonsense-mediated mRNA decay ${ }^{31,32}$. We have previously demonstrated that $\mathrm{uL} 3$ is also a key determinant in cellular stress response to common chemoterapeutic drugs as 5-FU, $\mathrm{OHP}$ and Act D in $p 53$-mutated lung and colon cancer cells ${ }^{8,9}$. Restoration of the uL3 protein level re-sensitize the resistant cells to drugs by regulating the levels of p21 and CBS proteins ${ }^{14,15}$. Published evidences from our group indicates that Act D is able to trigger nucleolar stress modulating uL3 levels and in turn p21 activity with consequent cell cycle arrest or apoptosis ${ }^{9}$. Here, we show that in condition of Act D induced nucleolar stress, ribosome free uL3 
$\mathbf{a}$

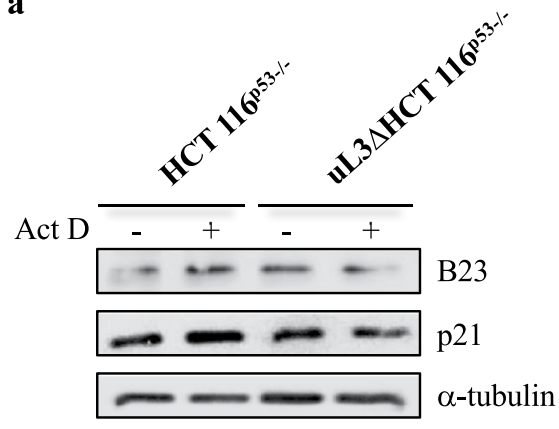

b

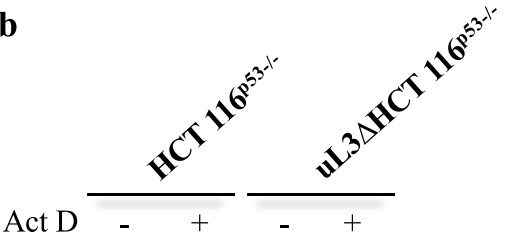

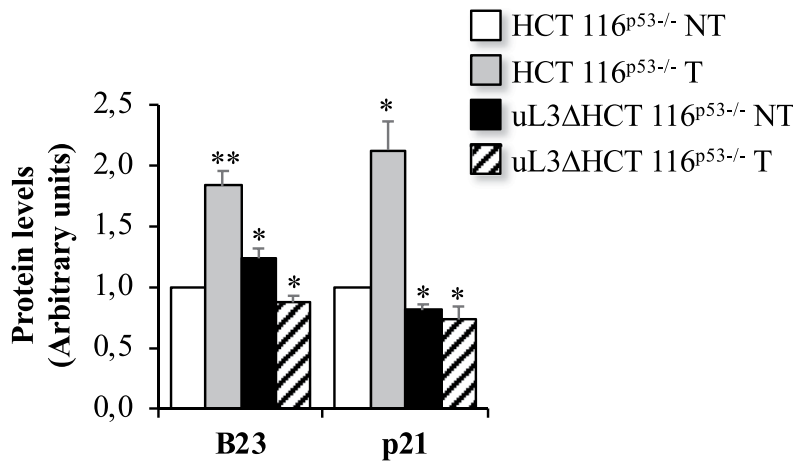

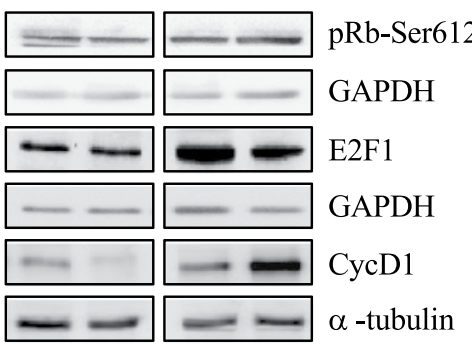

c

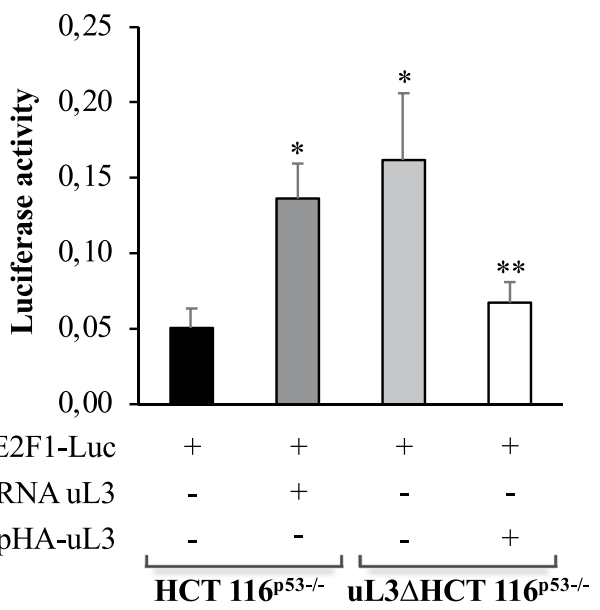

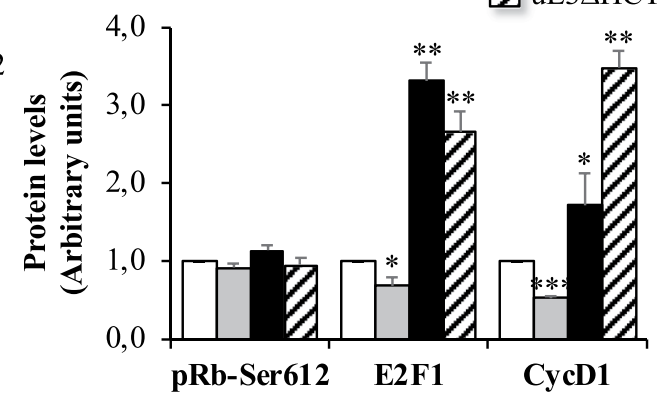

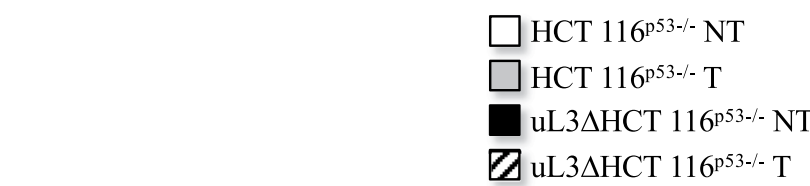

d

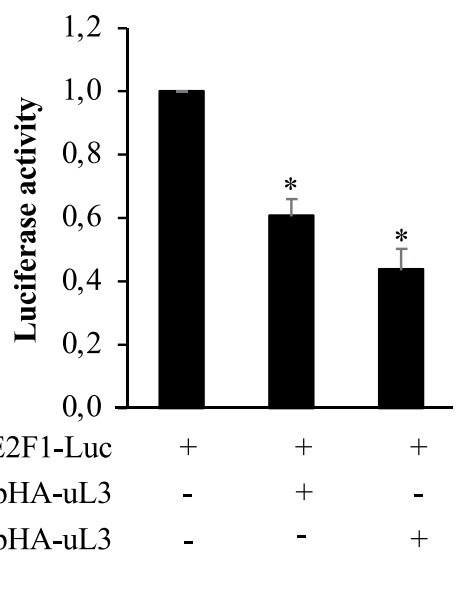

Figure 5. Effects of uL3 on cell cycle related gene expression and E2F1 promoter activity. (a) Representative western blotting of B23 and p21, (b) pRb-Ser612, E2F-1 and CycD1. HCT $116^{\mathrm{p} 53-1-}$ and uL $3 \Delta$ HCT $116^{\mathrm{p} 53-1-}$ cells were treated with Act D $5 \mathrm{nM}$ for $18 \mathrm{~h}$. After the treatment, protein extracts from the samples were analyzed by western blotting with antibodies against indicated proteins. $\alpha$-tubulin and GAPDH were used as loading controls. Full-length blots are presented in Supplementary Figs S9 and S10. Quantification of signals is shown. Bars represent the mean of triplicate experiments; error bars represent the standard deviation. $* * \mathrm{P}<0.01$, $* \mathrm{P}<0.05$ vs. untreated HCT $116^{\mathrm{p} 53-I-}$ cells set at 1 . (c) HCT $116^{\mathrm{p} 53-1-}$ were transiently co-transfected with E2F1 promoter-driven reporter construct pGL2-AN (E2F1-Luc) and uL3 siRNA, uL3 $\Delta$ HCT $116^{\mathrm{p}^{53-1-}}$ cells were transiently co-transfected with E2F1-Luc and pHA-uL3. Luciferase activities were measured after $24 \mathrm{~h}$. Data are presented after normalizing transfection efficiency using the Renilla luciferase reporter gene. Bars represent the mean of triplicate experiments; error bars represent the standard deviation. $* * \mathrm{P}<0.01, * \mathrm{P}<0.05$ vs. E2F1-Luc transfected cells. (d) HCT $116^{\mathrm{p} 53-/-}$ cells were transiently transfected with E2F1-Luc alone or with $1 \mu \mathrm{g}$ or $2 \mu \mathrm{g}$ of pHA-uL3. Luciferase activities were measured after $24 \mathrm{~h}$. Data are presented after normalizing transfection efficiency using the Renilla luciferase reporter gene. Bars represent the mean of triplicate experiments; error bars represent the standard deviation. $* \mathrm{P}<0.05$ vs. E2F1-Luc transfected cells set at 1 . 
a

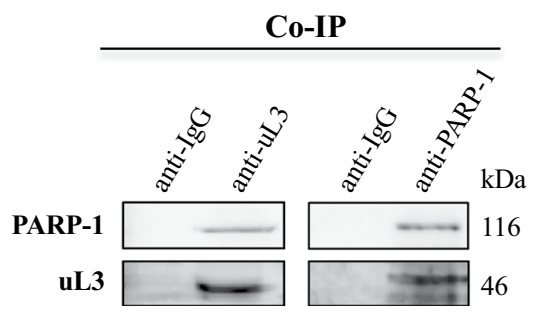

b

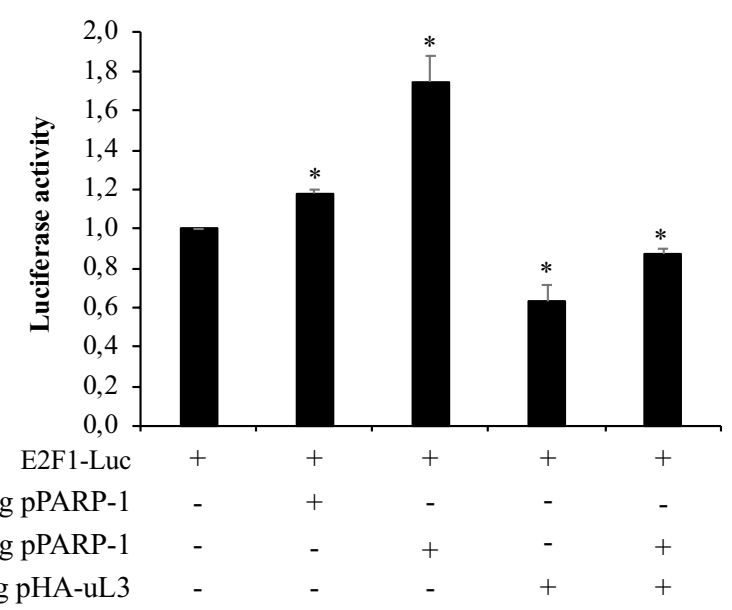

Figure 6. uL 3 binds PARP-1 and regulates PARP-1 mediated E2F1 promoter activation. (a) In vivo binding of uL3 and PARP-1. uL3 and PARP-1 were specifically immunoprecipitated from HCT $116^{\mathrm{P}^{53-1-}}$ cell extracts with antibodies against the endogenous uL3 and PARP-1. Immunoprecipitates were separated by SDS-PAGE and immunoblotted with antibodies versus PARP-1 and uL3 respectively. Note the absence of signal in IgG immunocomplex. Full-length blots are presented in Supplementary Fig. S11. (b) HCT 116 $\mathrm{p}^{53-1-}$ cells were transiently transfected with E2F1 promoter-driven reporter construct pGL2-AN (E2F1-Luc) alone or cotransfected with 0.5 or $1 \mu \mathrm{g}$ of pPARP- 1 plasmid or $1 \mu \mathrm{g}$ of pHA-uL3 alone or in combination with $1 \mu \mathrm{g}$ of pPARP-1 plasmid. Luciferase activities were measured after $24 \mathrm{~h}$. Data are presented after normalizing transfection efficiency using the Renilla luciferase reporter gene. Bars represent the mean of triplicate experiments; error bars represent the standard deviation. $* \mathrm{P}<0.05$ vs. E2F1-Luc transfected cells set at 1.

translocates from the nucleolus to the nucleoplasm where it can exert extra-ribosomal functions (Fig. 2a). To better characterize this alternative role, we performed experiments in colon cancer cells expressing $\mathrm{uL} 3$ and in a sub-line stably depleted of $\mathrm{UL} 3$ (uL3 $\Delta$ HCT $116^{\mathrm{p} 53-1-}$ cells). We show that when uL3 expression was switched off an increase in cell migration was observed as demonstrated by the enhanced wound healing ability of these cells compared to that observed in HCT $116^{\mathrm{p} 53-/-}$ cells (Fig. 1a). Starting from this observation and the concept that EMT is a tissue remodeling process reactivated during wound healing and in cancer $^{33}$ we analyzed the expression profile of E-cadherin and vimentin proteins that are considered two key markers associated with $\mathrm{EMT}^{33}$.

In this study, we found that in uL3 $\Delta$ HCT $116^{\mathrm{p53-l-}}$ cells the low expression of uL3 is associated to the EMT transition (Fig. 1b,c), which results in a more aggressive, invasive cancer phenotype. These data indicate a role for uL3 loss in cancer as an inducer of EMT. Accordingly, pharmacological inhibition of Pol I, which causes the accumulation of $\mathrm{uL} 3$ ribosome-free form and activates its extra-ribosome functions ${ }^{5}$, lowered the presence of pro-invasive mesenchymal proteins and reduced cellular invasiveness ${ }^{34}$.

Our previous data demonstrated that uL3 positively targets $\mathrm{p} 21$ to induce cell cycle arrest and/or apoptosis. Consistent with the known function of p21 in inhibition of EMT ${ }^{35}$, it is plausible that the observed EMT upon depletion of uL3 was due to consequent lower levels of p21.

Acquisition of a migratory phenotype and EMT are hallmarks of human carcinoma cells that may be interconnected by molecular pathways controlling cell cycle progression ${ }^{36}$. By RT-qPCR experiments we demonstrated that in cells expressing uL3, Act D caused the down-regulation of E2F1 gene expression which was associated to a decreased expression of Cyclin D1 and the up-regulation of pro-apoptotic gene Bax (Fig. 3a,c). It has been demonstrated that E2F1 plays a central role in the control of the expression of Cyclin D1. The human Cyclin D1 promoter contains an E2F1 consensus site and E2F1 can repress Cyclin D1 gene expression ${ }^{37}$. Our data strongly suggest that $\mathrm{UL} 3$ is able to regulate E2F1 amount which in turn controls the expression of Cyclin D1.

In addition, it has been shown that E2F1 can induce apoptosis through a number of p53-independent mechanisms mainly due to E2F-mediated regulation of various pro-apoptotic genes ${ }^{38}$. According to this, the observed downregulation of E2F1 expression during nucleolar stress, required for apoptosis ${ }^{39}$, associated to a strong increase of the pro-apoptotic protein Bax (Fig. 3c). 
Interestingly, in cells in which uL3 expression was switched off the treatment with Act D showed different effects; in fact, it was associated to the up-regulation of Cyclin D1, E2F1 and Bcl-2 gene (Figs 3b,d and 5b). These data clearly indicate that $\mathrm{UL} 3$ is essential to mediate cell cycle arrest induced by Act $\mathrm{D}^{9}$ by specifically regulating the expression of cell cycle (E2F1 and Cyclin D1) and cell proliferation (Bax and Bcl-2) genes.

Important to note that the phosphorylation status of $\mathrm{Rb}$ was not affected by Act $\mathrm{D}$ treatment in both cell lines (Fig. 5) indicating that the regulatory mechanisms mediated by uL3 of E2F1 activity differ from those generally reported $^{11,21}$.

Hyperactivation of E2F1 observed in absence of $\mathrm{UL} 3$, has been shown to frequently contribute to malignant progres$\operatorname{sion}^{40}$. In accordance with these results, the lack of uL3 was associated to a strong increase of Cyclin D1 which correlates with a marked increase in cell motility and EMT transition observed in these cells. Cyclin D1, in fact, apart from its role in cell cycle dependent phosphorylation of $\mathrm{Rb}$ protein, plays a central role in the transcriptional regulation of genes involved in cell migration independently from its ability to interact with CDKs. More specifically, Cyclin D1 participates in RhoA-ROCK pathway by binding directly to $\mathrm{p} 27$ with consequent inhibition of the pathway. Inhibition of the Rho/ ROCK2 pathway leads to a decrease in number of focal adhesion as well as actin stress fibers that results in increased cell motility ${ }^{41}$. The observed up-regulation of Cyclin D1 represents also a mechanism of chemoresistance. These data are in line with previous findings demonstrating that the over-expression of Cyclin D1 results in drug resistance in different cancers $^{20}$. In particular, it has been shown that elevated Cyclin D1 expression in conditions of p53 deficiency promotes chemoresistance in Mantle Cell Lymphoma ${ }^{42}$. In addition, numerous evidences have demonstrated that the attenuation of Cyclin D1 expression resulted in enhanced chemosensitivity to anticancer drugs ${ }^{20}$. The expression of Cyclin D1 is highly regulated at different levels ${ }^{23}$. Here, we report a key role of uL3 in the control of Cyclin D1 intracellular amounts. In cells silenced of uL3, the stability of Cyclin D1 mRNA and protein was increased (Fig. 4a,b) and the levels of this protein were higher than in parental cell line (Fig. 5b). Furthermore, in HCT $116^{\mathrm{p} 53-1-}$ cells the up-regulation of uL3, after treatment with Act D, resulted in a reduction of about $50 \%$ in the Cyclin D1 protein levels (Fig. 5b). uL3 could regulate Cyclin D1 expression acting on the stability of mRNA and protein or indirectly by inhibiting E2F1 promoter transactivation (Fig. 5c, d). The uL3 mediated transcriptional regulation of E2F1 results in a reduction of E2F1 protein that is known positively regulated Cyclin D1 promoter activity ${ }^{22}$.

With the aim to examine the molecular mechanisms involved in the uL3 mediated down-regulation of E2F1 transcription we identified PARP-1, a nuclear enzyme essential for genomic stability and chromatin remodeling, as a new molecular target of uL3. Specifically, we demonstrated that uL3 and PARP-1 co-immunoprecipitate indicating that these proteins associate in vivo (Fig. 6a).

PARP-1 represents the main positive regulator of E2F1 in cells. Specifically, PARP-1 acts as a positive cofactor of E2F-1-mediated transcription. PARP-1 does not directly bind the E2F1 promoter but it interacts directly with E2F1 protein and increases the binding affinity of E2F1 to its consensus sequence ${ }^{25}$.

In addition, (ADP-ribosyl)ation status of E2F1 influences its ability to bind specific protein partners. To date, PARP-1 (ADP-ribosyl)ates E2F1 and in this way stabilizes the binding between E2F1 and other proteins as BIN1 tumor suppressor. When PARP-1 is deficient, hypo-poly(ADP-ribosyl)ated E2F1 releases the proapoptotic BIN1 and cells result more sensible to apoptosis ${ }^{43}$. To evaluate the role of uL3 in PARP-1 mediated activation of E2F1, we investigated the effects of PARP-1 on E2F1-mediated functions in the presence and absence of uL3.

Data from luciferase assay upon UL3 and PARP-1 co-expression show that uL3 acts as repressor of E2F1 promoter activity and suggest that $\mathrm{uL} 3$ could bind the positive regulator PARP-1 and sequester it from the E2F1 promoter (Fig. 6b).

Taken together these results led us to propose a model in which upon drug induced nucleolar stress, ribosome free $\mathrm{uL} 3$ accumulates in the nucleolus and translocates into the nucleoplasm. Here, uL3 becomes a repressor of E2F1 promoter activity. UL3 interacts with PARP-1 and it could prevent its binding to the E2F1 promoter inhibiting in this way its transactivation. In addition, uL3 negatively affects Cyclin D1 expression at mRNA and protein levels. The $\mathrm{uL} 3$ mediated inhibition of E2F1 transactivation could be responsible at least in part of the lower levels of Cyclin D1 observed in condition of Act D induced nucleolar stress (Fig. 7).

In conclusion, our data unveil E2F1 and Cyclin D1 inactivation as a novel uL3 mediated cell response to nucleolar stress-based anticancer treatments.

\section{Methods}

Cell cultures, DNA, transfections and drug treatments. HCT $116^{\mathrm{p}^{53-1-}}$ cells and uL3 $\mathrm{HCT} 116^{\mathrm{p} 53-1-}$ a cell line derived from HCT $116^{\mathrm{p} 53-/-}$ cells and stably silenced for $\mathrm{uL}^{10}{ }^{10}$, were cultured in Dulbecco's Modified Eagle's Medium (DMEM) supplemented with 10\% fetal bovine serum (FBS), 2 mM L-glutamine, penicillin-streptomycin $50 \mathrm{U} / \mathrm{ml}$.

Drug treatments were performed by adding to cells Act D (Sigma). Transfection of pHA-uL3 plasmid, pGFP-uL3 plasmid, PARP-1 plasmid (Addgene, cod. 111575) and pGL2-AN containing the entire E2F-1 promoter (Addgene, cod. 20950) was performed in cells using Lipofectamin 2000 as previously described ${ }^{44}$. siRNA transfections were performed using Oligofectamine Reagent (Invitrogen) according to the manufacturer's instructions.

Wound healing assay. Cell motility was assessed using a wound healing assay as previously reported ${ }^{8}$.

Fluorescence microscopy. HCT $116^{\mathrm{p} 53-1-}$ cells were plated on coverslips at a density of $2 \times 10^{4}$ cells per well into $35 \mathrm{~mm}$ tissue culture plates and treated with $5 \mathrm{nM}$ Act D. $18 \mathrm{~h}$ later, cells were analyzed as previously described ${ }^{14,45}$.

Image processing and fluorescence signal quantifications. Fluorescence images obtained from immunofluorescence were processed in ImageJ software (version $1.49 \mathrm{v}$ with 64 bit Java Platform; NIH) and 


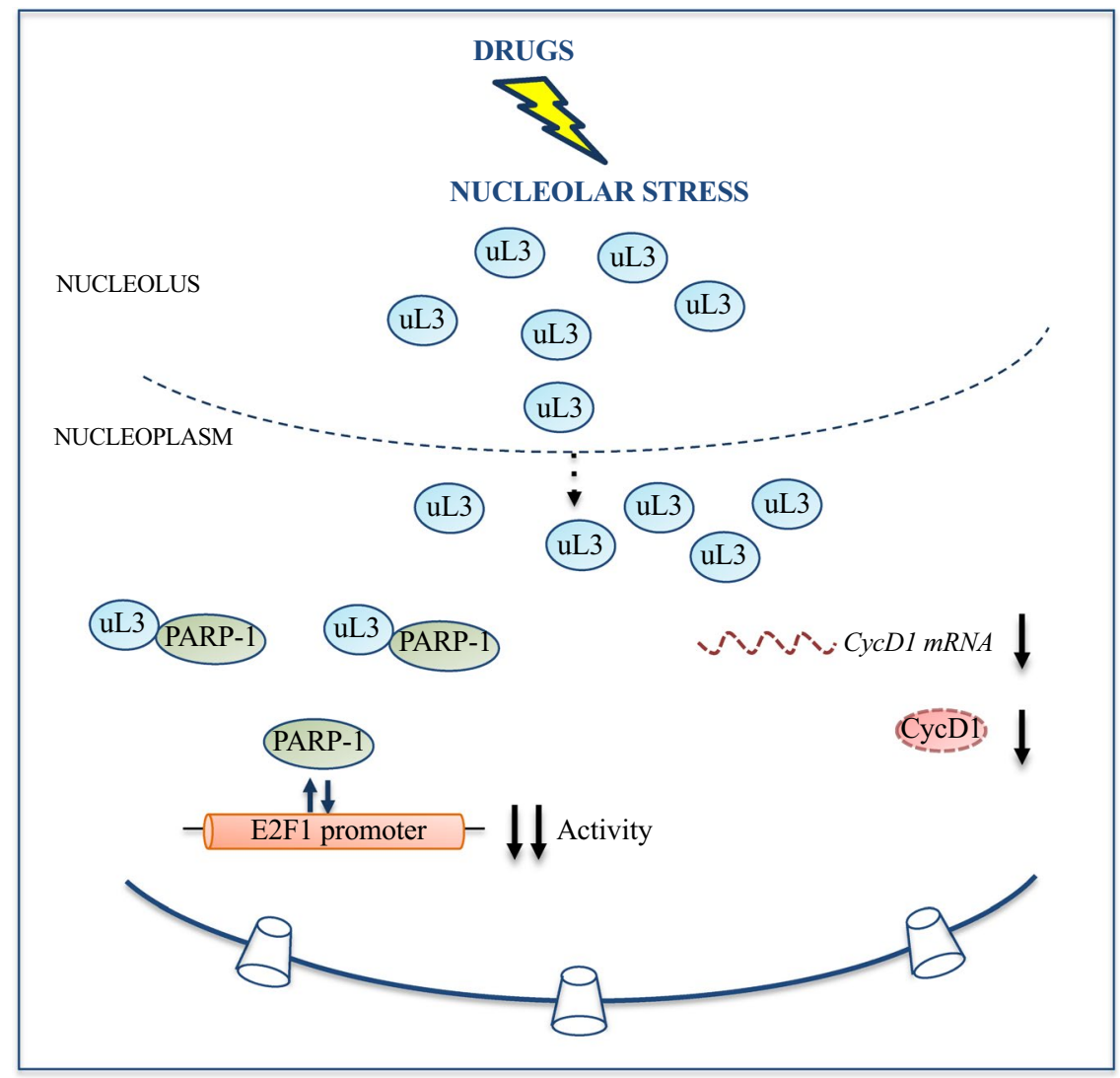

Figure 7. Schematic representation of proposed model. Upon drug induced nucleolar stress, ribosome free $\mathrm{uL} 3$ accumulates in the nucleolus and translocates into the nucleoplasm. Here, $\mathrm{uL} 3$ acts as a negative regulator of E2F1 promoter activity. In addition, uL3 inhibits Cyclin D1 protein half-life. These effects contribute to uL3 mediated cell response to nucleolar stress.

exported as TIFF mode files in red/green/blue (RGB) channels. To normalize individual cell differences, in general 30 cells were examined for quantification of average fluorescent intensity. The absolute fluorescence intensity and line plots were obtained from bit channel files before the images were transferred to RGB channel files. The relative fluorescence intensity (RFI) was calculated as $\mathrm{RFI}=\mathrm{Ncl} / \mathrm{Npl}$ where $\mathrm{Ncl}$ was the absolute intensity in the nucleolus area, $\mathrm{Npl}$ was the average the average intensity in nucleoplasmatic region.

RT-qPCR. Total RNA was isolated from cells as previously described ${ }^{46}$. RNA was first retrotranscribed using SensiFAST ${ }^{\text {TM }}$ cDNA Synthesis kit (Bioline) and then realtime PCR was carried out using SensiFAST SYBER ${ }^{\circledR}$ No-ROX kit. The primers are indicated in Table 1. The comparative Ct method was used to calculate the relative abundance of the mRNA and compared with that of $\beta$-actin expression ${ }^{47}$.

Nucleolar isolation. HCT $116^{\mathrm{p} 53-/-}$ cells plated in $100 \mathrm{~mm}$ petri dishes were washed twice with $20 \mathrm{~mL}$ cold

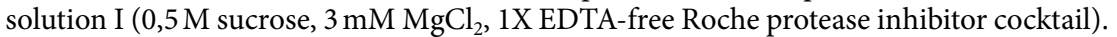

Collected cells were sonicated on ice at $50 \%$ power, $10 \mathrm{~s}$ on, $10 \mathrm{~s}$ off, for five cycles. The sonicated cell suspension was layered over 1,4 $\mathrm{mL}$ precooled solution II ( $1 \mathrm{M}$ sucrose, $3 \mathrm{mM} \mathrm{MgCl}_{2}$, 1X EDTA-free Roche protease inhibitor cocktail) and centrifuged at $1800 \times \mathrm{g}$ for $10 \mathrm{~min}$ at $4^{\circ} \mathrm{C}$. The resulting pellet contained the isolated nucleoli. The samples were resuspended in $200 \mu \mathrm{l}$ of $8 \mathrm{M}$ urea and incubated at $56^{\circ} \mathrm{C}$ for $40 \mathrm{~min}$. Then, each sample was analyzed by western blotting.

Immunoprecipitation and western blotting. Immunoprecipitation assay was performed as previously reported ${ }^{48}$. Briefly, whole cell lysate $(1 \mathrm{mg})$ was incubated with $30 \mu \mathrm{l}$ of protein A/G agarose beads coated with 5 $\mu \mathrm{g}$ of anti-uL3 (Primm, Milan, Italy) at $4^{\circ} \mathrm{C}$ for $12 \mathrm{~h}$. The beads were washed and boiled in the SDS sample buffer. The eluted proteins were loaded on $12 \%$ SDS-PAGE and detected by western blotting.

Western blotting analysis was performed as previously reported ${ }^{49}$. The membranes were challenged with anti-E2F1 (Elabscience), anti-uL3 (Primm, Milan, Italy), anti-PARP-1, anti-GAPDH (Cell signaling), anti-B23, anti-p21, anti- $\alpha$-tubulin, anti- $\beta$-actin, anti-nucleolin, anti-vinculin, anti-HA (Santa Cruz Biotechnology). Proteins were visualized with enhanced chemiluminescence detection reagent according to the manufacturer's instructions $\left(\right.$ Elabscience $^{\circledR}$ ).

Luciferase assays. Luciferase assays were performed as previously reported ${ }^{8}$. 
Protein half-life analysis. Protein half-life analysis was performed as previously reported ${ }^{50}$. Briefly, cells were treated with Cycloheximide (CHX, Sigma-Aldrich, St. Louis, MO, USA) 0,1 mg/ml for different times, and subsequently harvested and lysed using RIPA lysis buffer (50 mM Tris-HCl pH 7.4, 1\% NP40, 0,5\% Na-deoxycolate, $150 \mathrm{mM} \mathrm{NaCl}, 1 \mathrm{mM}$ Na3VO4, $1 \mathrm{mM} \mathrm{NaF}$, 1X EDTA-free Roche protease inhibitor cocktail). Protein extracts from samples were analyzed by western blotting.

Statistical analysis. Statistical analysis was performed as previously reported ${ }^{51}$. For image quantification, GraphPad Prism software (version 8.0) was used to analyse and plot all data. Statistical analysis was performed with two-tailed unpaired $t$-test with $95 \%$ confidence interval. In box and whisker plots, the box showed the top and bottom quartiles (25-75\%) with a line at the median and the whiskers showed the minimum to the maximum values of all data. $P$-values indicated the significances of differences.

Received: 28 June 2019; Accepted: 1 October 2019;

Published online: 28 October 2019

\section{References}

1. Evan, G. I. \& Vousden, K. H. Proliferation, cell cycle and apoptosis in cancer. Nature 411, 342-348, https://doi.org/10.1038/35077213 (2001).

2. Montanaro, L., Trere, D. \& Derenzini, M. Nucleolus, ribosomes, and cancer. The American journal of pathology 173, 301-310, https:// doi.org/10.2353/ajpath.2008.070752 (2008).

3. Boulon, S., Westman, B. J., Hutten, S., Boisvert, F. M. \& Lamond, A. I. The nucleolus under stress. Molecular cell 40, 216-227, https:// doi.org/10.1016/j.molcel.2010.09.024 (2010).

4. Boisvert, F. M., van Koningsbruggen, S., Navascues, J. \& Lamond, A. I. The multifunctional nucleolus. Nature reviews. Molecular cell biology 8, 574-585, https://doi.org/10.1038/nrm2184 (2007).

5. Russo, A. \& Russo, G. Ribosomal Proteins Control or Bypass p53 during Nucleolar Stress. International journal of molecular sciences 18, https://doi.org/10.3390/ijms18010140 (2017)

6. Xu, X., Xiong, X. \& Sun, Y. The role of ribosomal proteins in the regulation of cell proliferation, tumorigenesis, and genomic integrity. Sci China Life Sci 59, 656-672, https://doi.org/10.1007/s11427-016-0018-0 (2016).

7. Russo, A. et al. Human $\mathrm{rpL} 3$ induces $\mathrm{G}(1) / \mathrm{S}$ arrest or apoptosis by modulating p21 (waf1/cip1) levels in a p53-independent manner. Cell cycle (Georgetown, Tex.) 12, 76-87, https://doi.org/10.4161/cc.22963 (2013).

8. Esposito, D. et al. Human rpL3 plays a crucial role in cell response to nucleolar stress induced by 5-FU and L-OHP. Oncotarget 5, 11737-11751, https://doi.org/10.18632/oncotarget.2591 (2014).

9. Russo, A. et al. Regulatory role of rpL3 in cell response to nucleolar stress induced by Act D in tumor cells lacking functional p53. Cell cycle (Georgetown, Tex.) 15, 41-51, https://doi.org/10.1080/15384101.2015.1120926 (2016).

10. Pagliara, V. et al. 5-FU targets rpL3 to induce mitochondrial apoptosis via cystathionine-beta-synthase in colon cancer cells lacking p53. Oncotarget 7, 50333-50348, https://doi.org/10.18632/oncotarget.10385 (2016)

11. Bertoli, C., Skotheim, J. M. \& de Bruin, R. A. Control of cell cycle transcription during G1 and S phases. Nature reviews. Molecular cell biology 14, 518-528, https://doi.org/10.1038/nrm3629 (2013).

12. Burke, J. R., Deshong, A. J., Pelton, J. G. \& Rubin, S. M. Phosphorylation-induced conformational changes in the retinoblastoma protein inhibit E2F transactivation domain binding. The Journal of biological chemistry 285, 16286-16293, https://doi.org/10.1074/ jbc.M110.108167 (2010).

13. Poppy Roworth, A., Ghari, F. \& La Thangue, N. B. To live or let die - complexity within the E2F1 pathway. Molecular \& cellular oncology 2, e970480, https://doi.org/10.4161/23723548.2014.970480 (2015).

14. Russo, A. et al. Enhancement of 5-FU sensitivity by the proapoptotic rpL3 gene in p53 null colon cancer cells through combined polymer nanoparticles. Oncotarget 7, 79670-79687, https://doi.org/10.18632/oncotarget.13216 (2016).

15. Russo, A., Saide, A., Smaldone, S., Faraonio, R. \& Russo, G. Role of uL3 in Multidrug Resistance in p53-Mutated Lung Cancer Cells. International journal of molecular sciences 18, https://doi.org/10.3390/ijms18030547 (2017).

16. Thiery, J. P., Acloque, H., Huang, R. Y. \& Nieto, M. A. Epithelial-mesenchymal transitions in development and disease. Cell 139, 871-890, https://doi.org/10.1016/j.cell.2009.11.007 (2009).

17. Liang, Q. et al. CDK5 is essential for TGF-beta1-induced epithelial-mesenchymal transition and breast cancer progression. Scientific reports 3, 2932, https://doi.org/10.1038/srep02932 (2013).

18. Bendris, N., Lemmers, B. \& Blanchard, J. M. Cell cycle, cytoskeleton dynamics and beyond: the many functions of cyclins and CDK inhibitors. Cell cycle (Georgetown, Tex.) 14, 1786-1798, https://doi.org/10.1080/15384101.2014.998085 (2015).

19. Ratnadiwakara, M. \& Änkö, M. mRNA Stability Assay Using Transcription Inhibition by Actinomycin D in Mouse Pluripotent Stem Cells. Bio-protocol 8(21), e3072, https://doi.org/10.21769/BioProtoc.3072 (2018).

20. Kothari, V. \& Mulherkar, R. Inhibition of cyclin D1 by shRNA is associated with enhanced sensitivity to conventional therapies for head and neck squamous cell carcinoma. Anticancer Res 32, 121-128 (2012).

21. Giacinti, C. \& Giordano, A. RB and cell cycle progression. Oncogene 25, 5220-5227, https://doi.org/10.1038/si.onc.1209615 (2006).

22. Guo, Z. Y. et al. The elements of human cyclin D1 promoter and regulation involved. Clin Epigenetics 2(2), 63-76, https://doi. org/10.1007/s13148-010-0018-y (2011).

23. John, R. R., Malathi, N., Ravindran, C. \& Anandan, S. Mini review: Multifaceted role played by cyclin D1 in tumor behavior. Indian J Dent Res 28, 187-192, https://doi.org/10.4103/ijdr.IJDR_697_16 (2017).

24. Muller, H. et al. Induction of S-phase entry by E2F transcription factors depends on their nuclear localization. Mol Cell Biol 17, 5508-5520, https://doi.org/10.1128/mcb.17.9.5508 (1997).

25. Simbulan-Rosenthal, C. M. et al. PARP-1 binds E2F-1 independently of its DNA binding and catalytic domains, and acts as a novel coactivator of E2F-1-mediated transcription during re-entry of quiescent cells into $S$ phase. Oncogene 22, 8460-8471, https://doi. org/10.1038/sj.onc.1206897 (2003).

26. Loreni, F., Mancino, M. \& Biffo, S. Translation factors and ribosomal proteins control tumor onset and progression: how? Oncogene 33, 2145-56, https://doi.org/10.1038/onc.2013.153 (2013).

27. Fancello, L., Kampen, K. R., Hofman, I. J., Verbeeck, J. \& De Keersmaecker, K. The ribosomal protein gene RPL5 is a haploinsufficient tumor suppressor in multiple cancer types. Oncotarget 8, 14462-14478, https://doi.org/10.18632/oncotarget.14895 (2017).

28. Vaarala, M. H. et al. Several genes encoding ribosomal proteins are over-expressed in prostate-cancer cell lines: confirmation of L7a and L37 over-expression in prostate-cancer tissue samples. Int J Cancer 78, 27-32 (1998).

29. Bee, A. et al. Ribosomal protein L19 is a prognostic marker for human prostate cancer. Clin Cancer Res 12, 2061-2065, https://doi. org/10.1158/1078-0432.CCR-05-2445 (2006).

30. Meskauskas, A. \& Dinman, J. D. Ribosomal protein L3: gatekeeper to the A site. Molecular cell 25, 877-888, https://doi.org/10.1016/j. molcel.2007.02.015 (2007). 
31. Cuccurese, M., Russo, G., Russo, A. \& Pietropaolo, C. Alternative splicing and nonsense-mediated mRNA decay regulate mammalian ribosomal gene expression. Nucleic Acids Res 33, 5965-5977, https://doi.org/10.1093/nar/gki905 (2005).

32. Russo, A. et al. Autoregulatory circuit of human rpL3 expression requires hnRNP H1, NPM and KHSRP. Nucleic Acids Res 39, 7576-7585, https://doi.org/10.1093/nar/gkr461 (2011).

33. Pastushenko, I. \& Blanpain, C. EMT Transition States during Tumor Progression and Metastasis. Trends Cell Biol 29, 212-226, https://doi.org/10.1016/j.tcb.2018.12.001 (2019).

34. Drygin, D. et al. Targeting RNA polymerase I with an oral small molecule CX-5461 inhibits ribosomal RNA synthesis and solid tumor growth. Cancer research 71, 1418-1430, https://doi.org/10.1158/0008-5472.CAN-10-1728 (2011).

35. Li, X. L. et al. A p21-ZEB1 complex inhibits epithelial-mesenchymal transition through the microRNA 183-96-182 cluster. Molecular cell biology 34, 533-50, https://doi.org/10.1128/MCB.01043-13 (2014).

36. Garg, M. Epithelial-mesenchymal transition - activating transcription factors - multifunctional regulators in cancer. World J Stem Cells 5, 188-95, https://doi.org/10.4252/wjsc.v5.i4.188 (2013).

37. Klein, E. A. \& Assoian, R. K. Transcriptional regulation of the cyclin D1 gene at a glance. J Cell Biol 121, 3853-3857, https://doi. org $/ 10.1242 /$ jcs.03913 (2008).

38. Iaquinta, P. J. \& Lees, J. A. Life and death decisions by the E2F transcription factors. Curr Opin Cell Biol 19, 649-657, https://doi. org/10.1016/j.ceb.2007.10.006 (2007).

39. Pagliarini, V. et al. Downregulation of E2F1 during ER stress is required to induce apoptosis. Journal of Cell Science 128, 1166-1179, https://doi.org/10.1242/jcs.164103. (2015).

40. Ma, X. et al. Overexpression of E2F1 Promotes Tumor Malignancy And Correlates with TNM Stages in Clear Cell Renal Cell Carcinoma. PLoS One. 8, e73436, https://doi.org/10.1371/journal.pone.0073436 (2013).

41. Li, Z. et al. Cyclin D1 induction of cellular migration requires p27(KIP1). Cancer research 66, 9986-9994, https://doi. org/10.1158/0008-5472.CAN-06-1596 (2006).

42. Mohanty, S. et al. Cyclin D1 depletion induces DNA damage in mantle cell lymphoma lines. Leuk Lymphoma 58, 676-688, https:// doi.org/10.1080/10428194.2016.1198958 (2017).

43. Kumari, A. et al. Regulation of E2F1-induced apoptosis by poly(ADP-ribosyl)ation. Cell Death Differ. 22(2), 311-322, https://doi. org/10.1038/cdd.2014.146 (2015)

44. Russo, A. et al. hnRNP H1 and intronic G runs in the splicing control of the human rpL3 gene. Biochim Biophys Acta 1799, 419-428, https://doi.org/10.1016/j.bbagrm.2010.01.008 (2010).

45. Russo, A., Russo, G., Cuccurese, M., Garbi, C. \& Pietropaolo, C. The 3'-untranslated region directs ribosomal protein-encoding mRNAs to specific cytoplasmic regions. Biochim Biophys Acta 1763, 833-843, https://doi.org/10.1016/j.bbamcr.2006.05.010 (2006).

46. Russo, G. et al. Ribosomal protein L7a binds RNA through two distinct RNA-binding domains. Biochem J 385, 289-299, https://doi. org/10.1042/BJ20040371 (2005).

47. Schmittgen, T. D. \& Livak, K. J. Analyzing real-time PCR data by the comparative C(T) method. Nat Protoc 3, 1101-1108 (2008).

48. Russo, A. et al. cis-acting sequences and trans-acting factors in the localization of mRNA for mitochondrial ribosomal proteins. Biochim Biophys Acta 1779, 820-829, https://doi.org/10.1016/j.bbagrm.2008.08.006 (2008).

49. Russo, A. et al. Inhibition of granuloma-associated angiogenesis by controlling mast cell mediator release: role of mast cell protease-5. Br J Pharmacol 145, 24-33, https://doi.org/10.1038/sj.bjp.0706112 (2005).

50. Russo, A. et al. rpL3 promotes the apoptosis of p53 mutated lung cancer cells by down-regulating CBS and NFkappaB upon 5-FU treatment. Scientific reports 6, 38369, https://doi.org/10.1038/srep38369 (2016).

51. De Filippis, D. et al. Local administration of WIN 55,212-2 reduces chronic granuloma-associated angiogenesis in rat by inhibiting NF-kappaB activation. J Mol Med (Berl) 85, 635-645, https://doi.org/10.1007/s00109-007-0188-z (2007).

\section{Acknowledgements}

This work was supported by a grant from Regione Campania-POR Campania FESR 2014/2020 "Combattere la resistenza tumorale: piattaforma integrata multidisciplinare per un approccio tecnologico innovativo alle oncoterapie - Campania Oncoterapie" Project N. B61G18000470007 (A.R.); Fondo di ricerca di base FFABR-2017 (A.R. and G.R.); Ministero della Università e della Ricerca (MIUR).

\section{Author contributions}

A.P. and P.C. performed the experiments and analysed the data. A.R. and A.P. conceived, designed the experiments and interpreted the data. A.R. and G.R. coordinate, wrote and revised the manuscript.

\section{Competing interests}

The authors declare no competing interests.

\section{Additional information}

Supplementary information is available for this paper at https://doi.org/10.1038/s41598-019-51723-7.

Correspondence and requests for materials should be addressed to G.R. or A.R.

Reprints and permissions information is available at www.nature.com/reprints.

Publisher's note Springer Nature remains neutral with regard to jurisdictional claims in published maps and institutional affiliations.

(c) (i) Open Access This article is licensed under a Creative Commons Attribution 4.0 International

License, which permits use, sharing, adaptation, distribution and reproduction in any medium or format, as long as you give appropriate credit to the original author(s) and the source, provide a link to the Creative Commons license, and indicate if changes were made. The images or other third party material in this article are included in the article's Creative Commons license, unless indicated otherwise in a credit line to the material. If material is not included in the article's Creative Commons license and your intended use is not permitted by statutory regulation or exceeds the permitted use, you will need to obtain permission directly from the copyright holder. To view a copy of this license, visit http://creativecommons.org/licenses/by/4.0/.

(c) The Author(s) 2019 